\title{
Mucosal Ulcer
}

National Cancer Institute

\section{Source}

National Cancer Institute. Mucosal Ulcer. NCI Thesaurus. Code C118316.

A circumscribed loss of integ rity of the mucous membrane. 